\title{
Who's to Blame for Article Duplication?
}

Philip M. Davis

From the editor:

portal: Libraries and the Academy began life due to many concerns about scholarly journal publication. The following is an invited editorial. The concerns raised by the recent revelations of multiple publication of articles by Emerald/MCB University Press inspired a desire to offer our readership the thoughts of one of our own editorial board members. Mr. Davis' research uncovered this duplication, and here he provides us-as a profession—with some serious questions about our role and responsibilities in resisting this practice.

The recent discovery of systematic and covert article duplication in Emerald/MCB University Press journals has caused controversy in both academic and publishing circles. ${ }^{1}$

For over nearly three decades, libraries may have collectively spent hundreds of millions of dollars of the academy's money in purchasing content that they believed was original. Multiple copies of scholarly articles disrupt the record of publication, confuse accurate citation of articles, and may artificially raise the prestige of affected journals. Authors may discover that their work is associated with journals to which they have no affiliation nor for which they have any respect. The fact that editors and their boards claimed ignorance of duplication in their own journals begs the question whether peer review and editorial control even took place.

We may have just witnessed the very worst of academic publishing-a scenario in which commercial interests have outweighed editorial integrity and independence. At a time when academ-

We may have just witnessed the very worst of academic publishing - a scenario in which commercial interests have outweighed editorial integrity and independence. ics have expressed great fears that commercial publishers are exploiting the scholarly publishing process, it is far too easy to level blame entirely on Emerald without considering our own actions. Publishing does not exist without authors, reviewers, editors, editorial boards, and librarians; it oper- 
ates with the support, participation, and consent of the academic community. We ought to ask ourselves several questions.

First, why did it take nearly 30 years to uncover systematic duplication within this publisher's journals? Those researching the literature must have stumbled upon numerous examples, and those indexing the literature must have seen patterns. Were these findings known but just not reported, or were they reported but not acted upon?

Second, what was the role of editors and their boards during the process? With hundreds of examples of article duplication discovered in at least 73 of this publisher's journals, it is hard to believe that editors and their boards were completely unaware of this practice. Knowing that this was going on but taking no action to prevent it suggests complicity on the part of these individuals. Denying knowledge of the practice, on the other hand, admits a willful lack of editorial control and suggests that boards may have functioned as little more than window dressing. Either way, there was a failure to uphold the editorial process.

As an author, reviewer, and editorial board member myself, it is even more disturbing for me to realize that a great many articles were duplicated within library science journals. The fact that this happened on our own watch and on our own turf calls into question librarians' ability to manage our own literature, let alone the literature of others.

While librarians have been putting pressure on college faculty to reconsider their support (as editors, reviewers, and authors) for journals that do not sustain the interests of the academy, it does make one wonder whether librarians are practicing what they preach. It would be much too easy to point blame entirely at the publisher's behavior and absolve ourselves of any guilt and responsibility. To the extent that we have contributed to the problem, we are partially responsible for its consequences. At the very least, these instances of covert duplication call on us to redouble the scrutiny of our own literature even as we make demands on colleagues in other disciplines to do the same.

Philip M. Davis is life sciences bibliographer, Albert R. Mann Library, Cornell University, Ithaca, NY; he can be contacted via e-mail at: pmd8@cornell.edu.

\section{Notes}

1. Philip Davis, "The Ethics of Republishing: A Case Study of Emerald/MCB University Press Journals," Library Resources E Technical Services 49, 2 (forthcoming, spring 2005), http:/ / people.cornell.edu/pages/pmd8/ (accessed February 1, 2005); - , letter to the editor," Library Resources E Technical Services 49, 4 (forthcoming, summer 2005), http: / / people.cornell.edu/pages/pmd8/ (accessed February 1, 2005).

2. ARL, ACRL, and SPARC, "Create Change: Supporting Faculty and Librarian Action in Scholarly Communication," http:/ / www.createchange.org/home.html (accessed February 4, 2005). 